\title{
Impact of changes in the National Accounts and Economic Commentary for 2011 quarter 2
}

\author{
Peter Patterson, Pete Lee and Malindi Myers Office for National Statistics
}

\section{Summary}

This article summarises the effects of methodological, classification and other changes implemented in the Quarterly National Accounts for the second quarter of 2011, with which it is simultaneously published, consistent with the UK National Accounts Blue Book 2011, to be published in November.

\section{Introduction}

Every year, the ONS updates the UK national accounts through a process known as annual supply and use balancing. This brings together detailed data on the three approaches to measuring gross domestic product (GDP) and balances them by product and industry. Volume series are also updated so their reference and base years are moved forward, usually (but not always) by one year. At the same time, any major methodological or classification changes may be implemented within the accounts.

The publication incorporating these data is known as the Blue Book, which is preceded by a quarterly national accounts publication whereby the components of GDP are brought into line with the changes to follow.

\section{Main changes to methods}

Over the last few months, the ONS has published a series of articles discussing the changes to be made in this year's Blue Book. These were summarised in Everett (2011), 'Methods changes in the 2011 Blue Book'. The present article will discuss how these changes have affected the GDP data published in the 2011 quarter 2 Quarterly National Accounts. Subsequent articles will examine the effects on the institutional sector accounts and the supply and use balancing itself. The time series affected by revisions can be broken down into two distinct periods; 1997-2006, where the vast majority of revisions are due to new deflation methodology and the impact of the industrial reclassification described below and; 2007 onwards, where the data were fully 'open' for revisions due to new data and agreed methodology changes. 
Industrial reclassification - All national accounts data published with an industrial breakdown use the Standard Industrial Classification (SIC), consistent with the European NACE classification, to assign activities to industries. This classification is updated periodically to take account of changing industrial structures. Hitherto, the national accounts had been published on the basis of the 2003 SIC, but with this year's Blue Book, this is reclassified to the 2007 classification. This is the largest change to the industrial classification of the UK national accounts since the implementation of SIC92 in the 1995 Blue Book. For details, see Hughes et al (2009), 'Implementation of Standard Industrial Classification 2007: December 2009 update', Economic and Labour Market Review, December 2009, Volume 3, No 12. An industrial reclassification does not change top level aggregates (GDP, household final consumption and so on), rather the industrial breakdowns and weighting structures are different and better reflect the current structure of the economy. To incorporate these changes and to provide users a time series on the new SIC07 basis, data on the SIC03 basis were converted using factors provided by the ONS's Business Register, where businesses are classified on the old and new basis. The main correlator for these changes was turnover. This was used as a starting point for the conversion, with some additional manual adjustments made using available additional information. This has provided a time series back to 1997 on the new SIC07 basis - the data from 2008 onwards were collected on an SIC07 basis. The nature of this conversion, along with a re-balancing of supply and use tables, has meant that there have been some small revisions to the overall aggregates in periods prior to 2007.

Supply and use balancing - This will be discussed in more detail in an article to be published on $1^{\text {st }}$ November 2011, but this article will highlight the changes to the key components of GDP. Current price annual revisions to early periods (pre-2007) are very small. These are as a result of the limited rebalancing which took place. 2007 and 2008 were fully rebalanced, with large downward revisions to current price GDP in 2008 primarily being driven by new profits data from Her Majesty's Revenue and Customs (HMRC) which are at a significantly lower level than those used in Blue Book 2010.The balancing process has been applied to 2009 for the first time in the 2011 Blue Book. The annual level of current price GDP in 2009 is similar to that previously published, but the lower level of 2008 means that 2009 growth is less negative than previously published.

Deflation - One of the most significant improvements included in this year's Blue Book and associated publications is embodied in changes in the way deflation of nominal estimates to derive chained volume, or real, estimates of GDP and its components is carried out:

- there has been a movement from using components of the Retail Prices Index (RPI) to components of the Consumer Prices Index (CPI). This brings the UK National Accounts into line with best practice as set out in international guidance. The biggest effects here appear in estimates of household final consumption expenditure, but other expenditure components, as well as output estimates, are also affected

- additionally, there has been a standardisation of the level and source of deflation across large parts of the accounts, which has led to further changes. This standardisation has improved the coherence and consistency of the National Accounts. Rebalancing of supply and use tables has also led to a change in the product breakdowns of most components and, given that each product is deflated separately, this has also led to revisions to chained volume estimates.

Other things being equal, the theoretically expected impact of changing from RPI based deflators to CPI based ones would be to raise the calculated volume of GDP. However, as noted earlier, this is not the only change impacting on GDP estimates. For more detail regarding changes to deflation methodology, see Drew (2011) 'Deflation Improvements in the UK National Accounts'. 
New base and reference year - Normally, as part of the Blue Book process, the base year and reference year for chained volume estimates are moved forward by one year so that the estimates better reflect the industrial structures and prices currently seen within the economy. Unusually, in the 2007 and 2008 Blue Books, this process was suspended (for more detail see Beadle (2007) 'Modernising the UK's National Accounts', Economic and Labour Market Review, April 2007, Volume 1, No 4 and Humphries (2008) 'Modernisation of the UK's National Accounts: progress and plans for Blue Book and Pink Book 2008, Volume 2, No6). So the base and reference years were two years behind where they would normally be. In Blue Book 2009, the base year and reference year moved forward by two years, catching up by one year, but still leaving the base and reference periods one year behind where they would ideally have been. This is rectified as from the quarter two 2011 Quarterly National Accounts, where the base and reference years move forward by two years from 2006 to 2008 . It is planned to continue with the normal annual updating of base and reference periods from Blue Book 2012 onwards.

Re-referencing on its own does not cause revisions to real growth rates, but the rebasing process, taking on as it does new gross value added and product weights from the supply and use balancing process, will cause revisions to the growth rates of chained volume components.

\section{Main changes to the data and economic commentary}

Following these changes:

- there is relatively little alteration in current price GDP, in years up to and including 2007. By 2010, the level is estimated to be 0.2 per cent higher than in previously published estimates

- annual growth of the chained volume measure of GDP has been revised up in most years since 1997, though there are also some downward revisions. Annual average GDP growth over this period has been revised up by 0.2 percentage points.

\section{Chart 1: Revisions to annual GDP growth in volume terms (percentage points)}

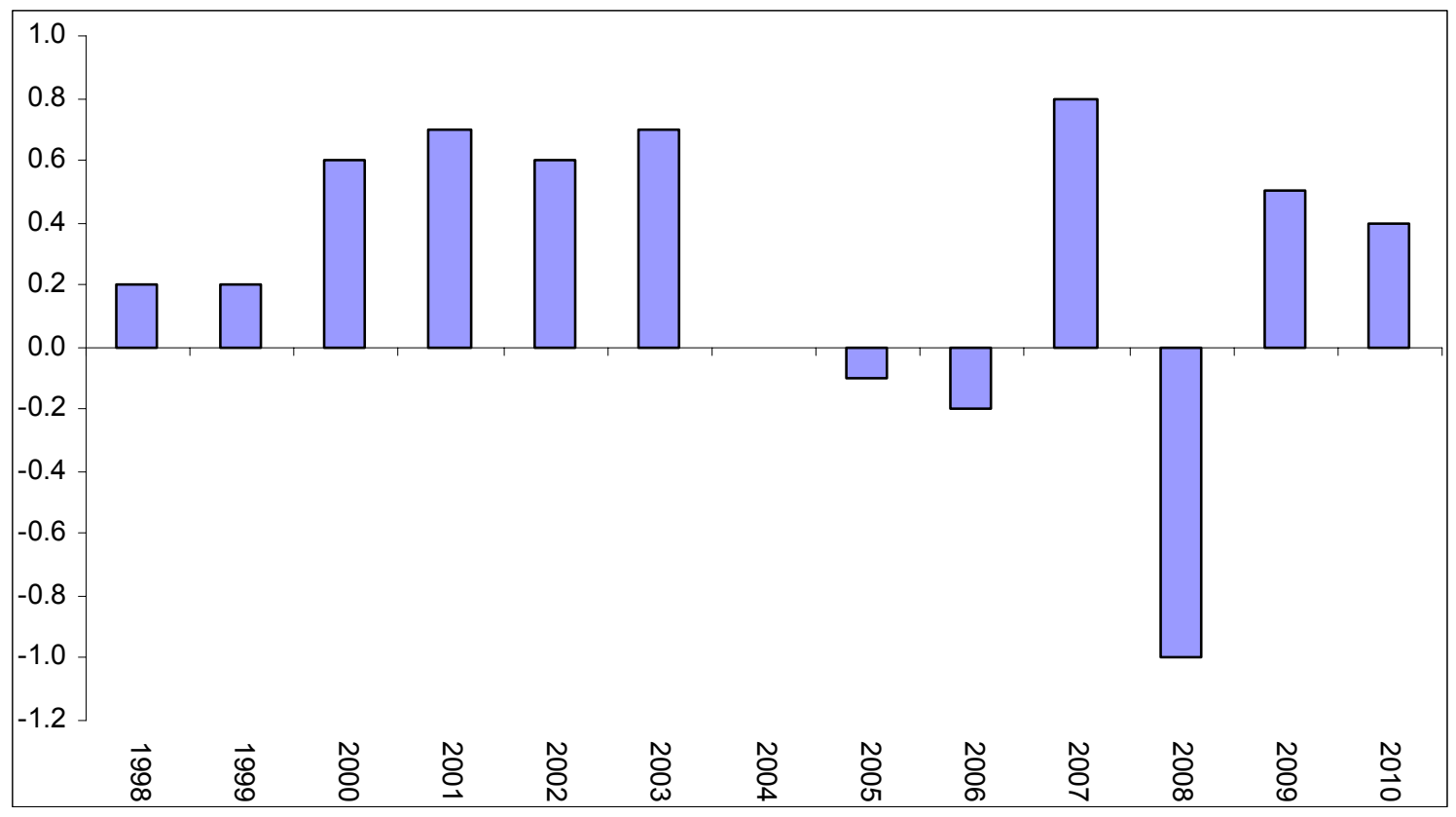


Table 1: Revisions to annual GDP growth rates

\begin{tabular}{|c|c|c|c|}
\hline Year & $\begin{array}{c}\text { Latest GDP } \\
\text { growth } \\
\text { estimates } \\
\text { (per cent) }\end{array}$ & $\begin{array}{c}\text { Previously } \\
\text { published } \\
\text { estimates } \\
\text { (per cent) }\end{array}$ & $\begin{array}{c}\text { Revisions } \\
\text { (percentage } \\
\text { points) }\end{array}$ \\
\hline 1998 & 3.8 & 3.6 & 0.2 \\
\hline 1999 & 3.7 & 3.5 & 0.2 \\
\hline 2000 & 4.5 & 3.9 & 0.6 \\
\hline 2001 & 3.2 & 2.5 & 0.7 \\
\hline 2002 & 2.7 & 2.1 & 0.6 \\
\hline 2003 & 3.5 & 2.8 & 0.7 \\
\hline 2004 & 3.0 & 3.0 & 0.0 \\
\hline 2005 & 2.1 & 2.2 & -0.1 \\
\hline 2006 & 2.6 & 2.8 & -0.2 \\
\hline 2007 & 3.5 & 2.7 & 0.8 \\
\hline 2008 & -1.1 & -0.1 & -1.0 \\
\hline 2009 & -4.4 & -4.9 & 0.5 \\
\hline 2010 & 1.8 & 1.4 & 0.4 \\
\hline
\end{tabular}

There are upward revisions to real GDP growth in each of the years 1998 to 2003, mainly reflecting the shift from RPI-based to CPI-based deflation for some components of household final consumption expenditure, as well as changes to deflation methodology affecting other expenditure components. Because inflation measured by the consumer prices index was generally lower than RPI-based measures, the revised price deflators now grow more slowly. For given levels of nominal GDP, real GDP growth was therefore somewhat higher.

The apparent slowdown in 2001 that was a feature of the initial estimates of growth at the time has gradually been eroded by data revisions. The latest data show that growth barely dipped below its long run average, although it was still weaker in 2001 and 2002 than in the previous few years.

During 2004-2006, there are only small revisions to estimated GDP growth because the CPI and $\mathrm{RPI}$ measures of inflation came closer into line during this period. The picture of a temporary deceleration in growth around 2005 is preserved.

Chart 2 illustrates that in many years household final consumption is the biggest contributor to the revisions to GDP growth. This stems from the impact of the move from an RPI to a CPI-based deflator, reclassification of some consumer goods and services between sub-sectors with different deflators, and the supply and use balancing process which particularly affects figures for 2008 and 2009.

Revisions to export and import growth have also altered the contribution of net trade to GDP growth in a number of years, particularly between 2007 and 2010. Gross fixed capital formation (GFCF) is not subject to the same scale of revisions seen by some other components, apart from 2009 and 2010 where figures have been amended as a result of the supply and use balancing process. 


\section{Chart 2: Revisions to GDP growth and the contributions of main expenditure components (percentage points)}

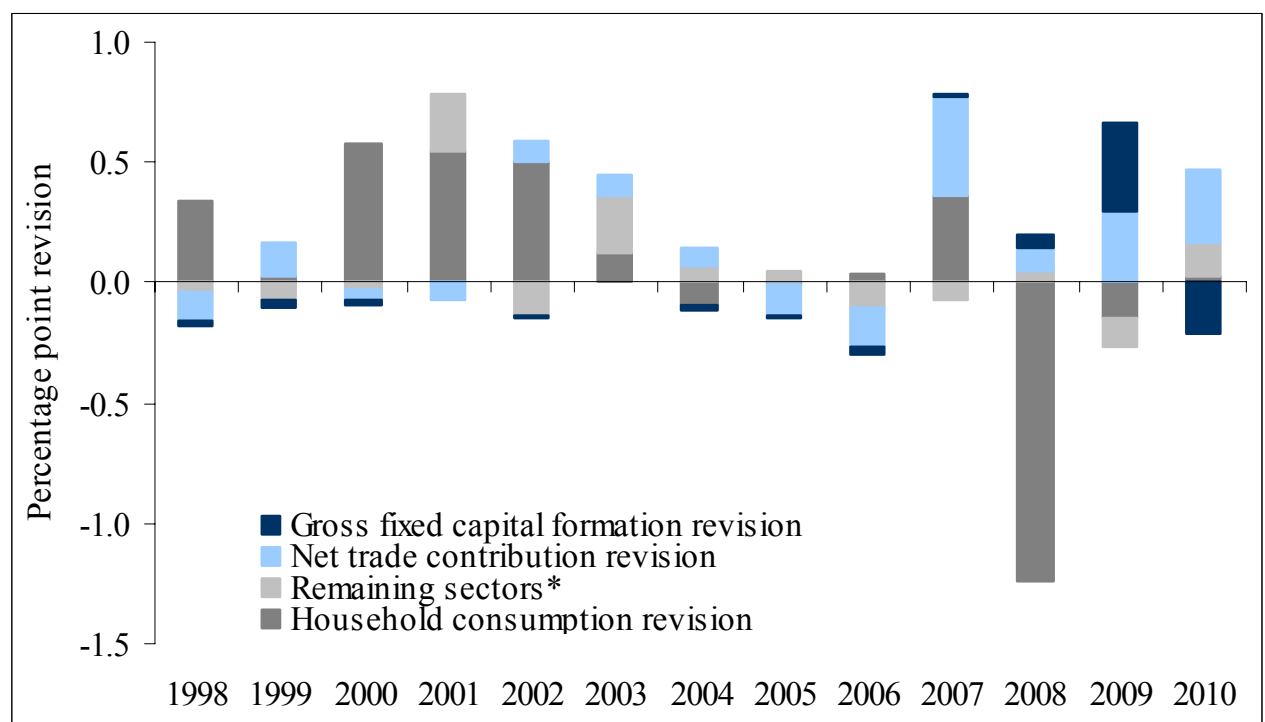

* Non-profit making institutions serving households, general government final consumption, inventories and valuables. The three sectors explicitly referred to in the chart account for around three quarters of the expenditure measure of GDP.

\section{GDP deflator}

As a result of the improvements to the method of deflation, the GDP deflator has generally been revised down, reflecting that for most of the years in the period covered RPI growth has been greater than in the CPI. In addition, trade deflators have been affected by the reclassification of products to the new CPA08 basis and there has been a methodological change to the way deflators are applied across the national accounts to make it more consistent across sectors and components. Finally, the supply and use balancing process has resulted in some elements of output being moved to different components or sectors, which have therefore been subject to different deflators, and this feeds through to a change in the aggregate deflator for GDP as a whole. 


\section{Chart 3: Revisions to annual GDP deflator growth (percentage points)}

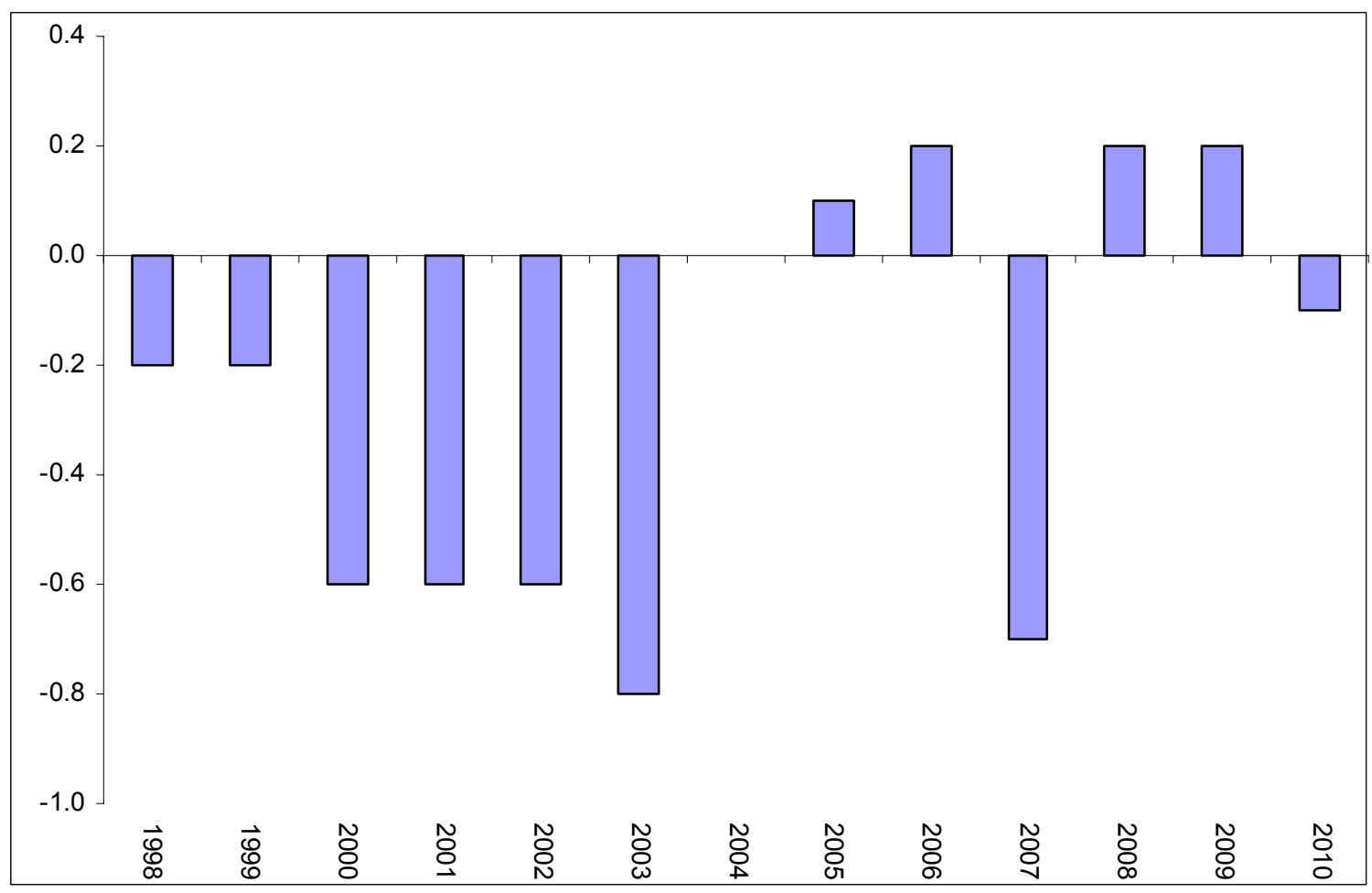

\section{Revisions during 2007 and subsequently}

The latest data contain significant revisions to the period 2007-2010. These include:

- $\quad$ an upward revision to real GDP growth in 2007

- $\quad$ a large downward revision to growth in 2008

- $\quad$ upward revisions to growth in both 2009 and 2010.

In 2007, real growth has been revised from 2.7 per cent to 3.5 per cent. The revisions are concentrated in household consumption and net overseas trade. Their respective contributions to GDP growth have both risen by 0.4 percentage points. They stem from changes in deflation methods and classification changes.

In 2008, the magnitude of the contraction in the economy is estimated to have increased from 0.1 per cent to 1.1 per cent. The main cause is the adoption of the latest information on company profits from HM Revenue and Customs. This leads to a much lower estimate of the income measure of GDP than in previously published data. The income measure is regarded as a reliable determinant of annual movements in GDP once the full set of underlying information has been incorporated. Accordingly, this new data has an important impact on the supply and use balancing process for reconciling the different estimates of GDP in 2008. The resulting downward revision affects the level of GDP measured in current prices and this feeds through into growth in the chained volume measure.

In addition, the impact of the change from RPI to CPI-based deflation also has a small negative impact on growth in 2008 as (unusually) inflation measured by the CPI was higher than RPI based estimates from September onwards in this year. 
The latest HMRC data on company profits in 2009 have also been incorporated into the income based GDP estimates for that year. Although the level of profits was similar to that underlying the previously published income estimate of GDP, growth in 2009 was raised because the level in 2008 has been reduced.

Revisions to annual GDP growth in 2010 are due to a combination of changes to the deflation methodology and industrial weights, in addition to new data, as would normally be received at this stage of the GDP publication cycle.

\section{Depth and timing of the downturn and recovery}

The revisions to GDP growth since 2006 are summarised in chart 4 and table 2 . They have implications for the estimated shape of the contraction and the subsequent recovery, as can be seen from chart 5 :

- growth in 2007 is estimated to have been stronger than previously published, so that the economy entered the downturn from a higher point

- the beginning of the downturn remains much the same with growth still first estimated to have become negative in 2008 Q2

- but the subsequent path of the economic contraction is now estimated to have been sharper and deeper. The fall in GDP from peak to trough is measured to have been 7.1 per cent , as compared with 6.4 per cent in previously published estimates

- growth is now estimated to have resumed in 2009 Q3, one quarter earlier than in previously published figures

- cumulative growth since 2009 Q2 is estimated to have been 0.3 percentage points greater than in previously published estimates. However, since 2010 Q3, GDP looks to have been broadly flat.

\section{Chart 4: Revisions to quarter-on-quarter GDP growth (percentage points)}

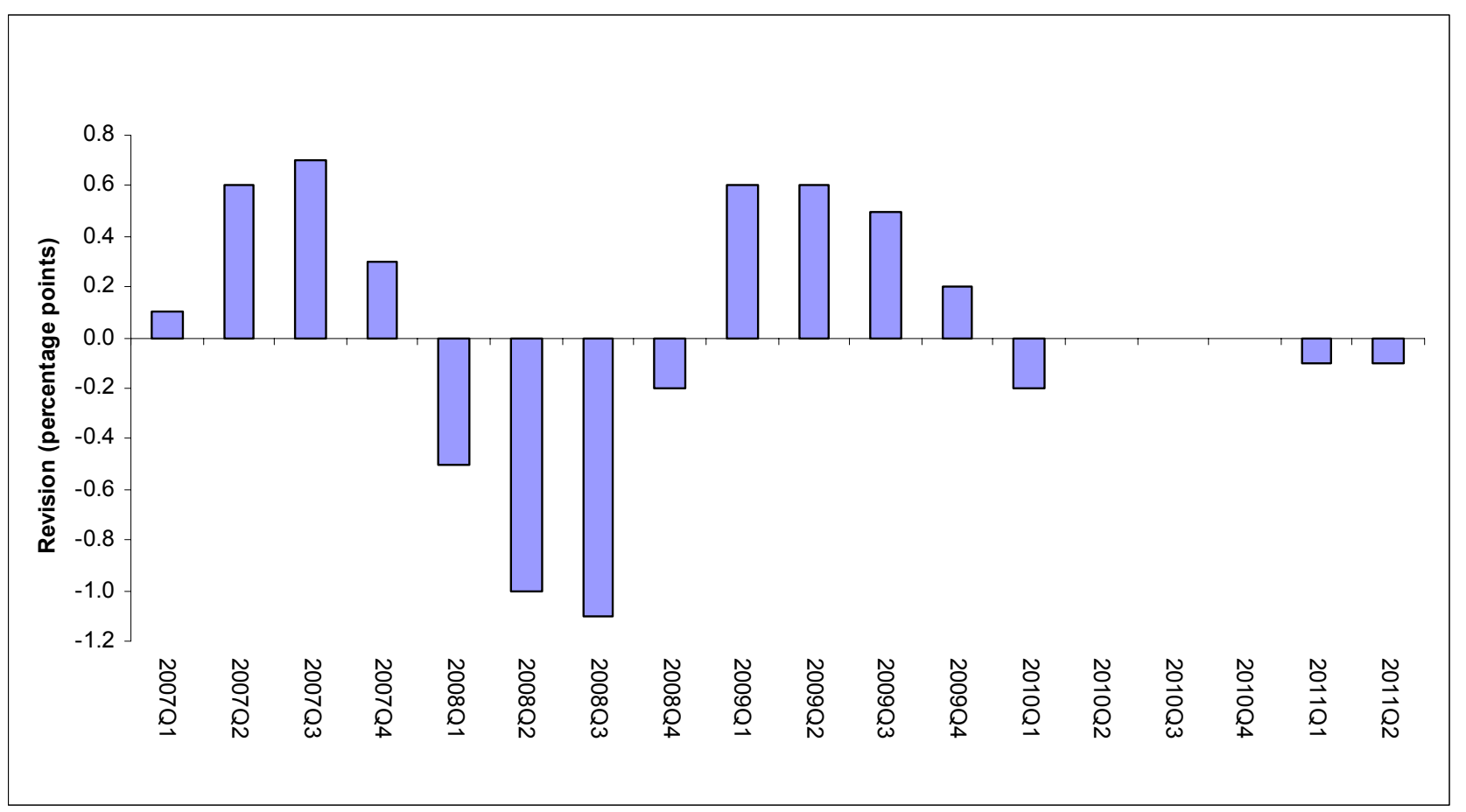


Table 2: Quarterly GDP growth rates and revisions

\begin{tabular}{|c|c|c|c|}
\hline Year & $\begin{array}{c}\text { Latest GDP } \\
\text { growth } \\
\text { estimates } \\
\text { (per cent) }\end{array}$ & $\begin{array}{c}\text { Previously } \\
\text { published } \\
\text { estimates } \\
\text { (per cent) }\end{array}$ & $\begin{array}{c}\text { Revisions } \\
\text { (percentage } \\
\text { points) }\end{array}$ \\
\hline 2007 Q1 & 1.1 & 1.0 & 0.1 \\
\hline 2007 Q2 & 1.2 & 0.6 & 0.6 \\
\hline 2007 Q3 & 1.2 & 0.5 & 0.7 \\
\hline 2007 Q4 & 0.6 & 0.3 & 0.3 \\
\hline 2008 Q1 & 0.0 & 0.5 & -0.5 \\
\hline 2008 Q2 & -1.3 & -0.3 & -1.0 \\
\hline 2008 Q3 & -2.0 & -0.9 & -1.1 \\
\hline 2008 Q4 & -2.3 & -2.1 & -0.2 \\
\hline 2009 Q1 & -1.6 & -2.2 & 0.6 \\
\hline 2009 Q2 & -0.2 & -0.8 & 0.6 \\
\hline 2009 Q3 & 0.2 & -0.3 & 0.5 \\
\hline 2009 Q4 & 0.7 & 0.5 & 0.2 \\
\hline 2010 Q1 & 0.2 & 0.4 & -0.2 \\
\hline 2010 Q2 & 1.1 & 1.1 & 0.0 \\
\hline 2010 Q3 & 0.6 & 0.6 & 0.0 \\
\hline 2010 Q4 & -0.5 & -0.5 & 0.0 \\
\hline 2011 Q1 & 0.4 & 0.5 & -0.1 \\
\hline 2011 Q2 & 0.1 & 0.2 & -0.1 \\
\hline
\end{tabular}

Chart 5 GDP growth through the economic contraction $(2008 q 1=100)$

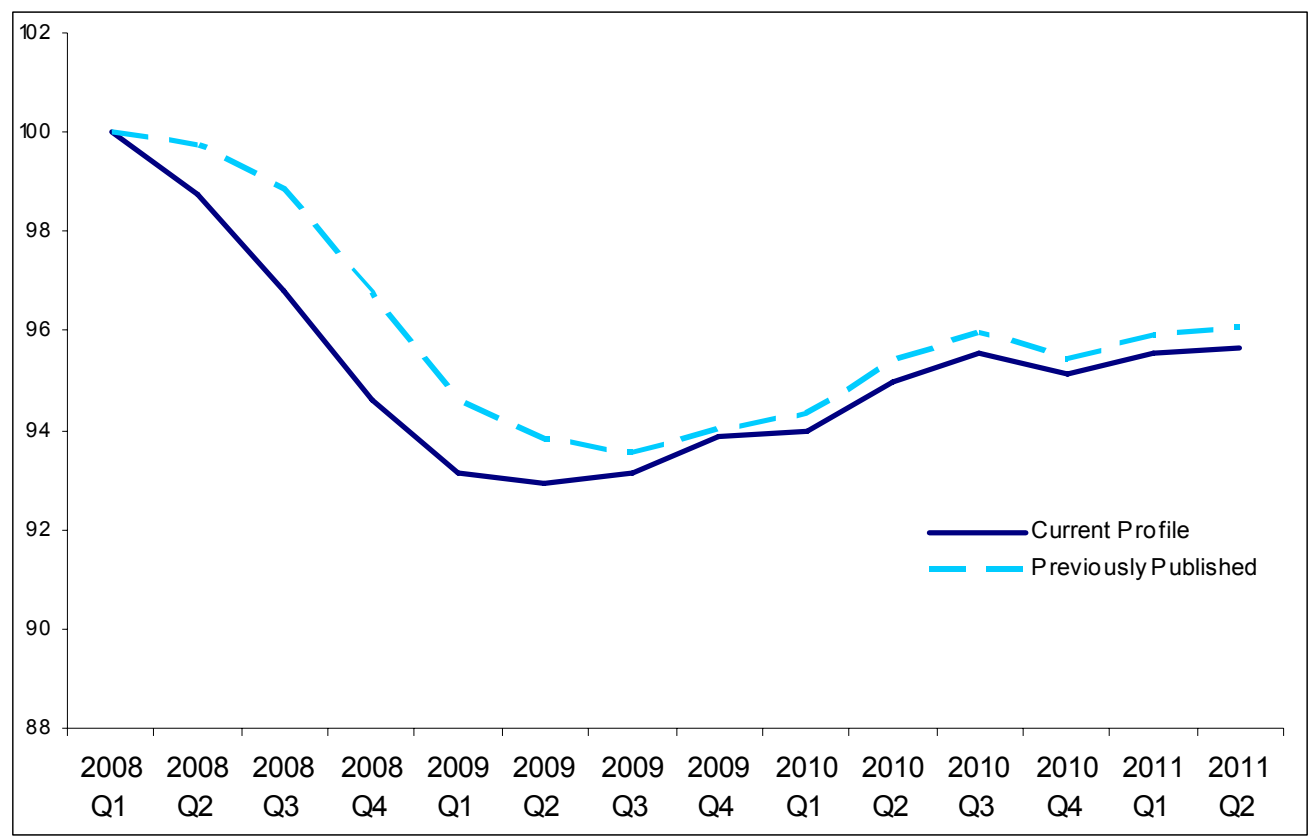




\section{Changes to the sectoral composition of growth}

\section{Expenditure components}

The switch from RPI to CPI-based deflation has affected a number of components of household spending. Because CPI inflation has been lower than RPI inflation in most years, this has on average boosted growth in the real level of household final consumption (chained volume measure). Chart 6 shows quarterly revisions to household final consumption expenditure data from 1997 to 2011 quarter one (for more information, please see Gittins and Clancy (2011), 'Blue Book 2011 - Improvements to Household Expenditure Estimates'.

\section{Chart 6 Revisions to household final consumption expenditure growth rates, chained volume measures}

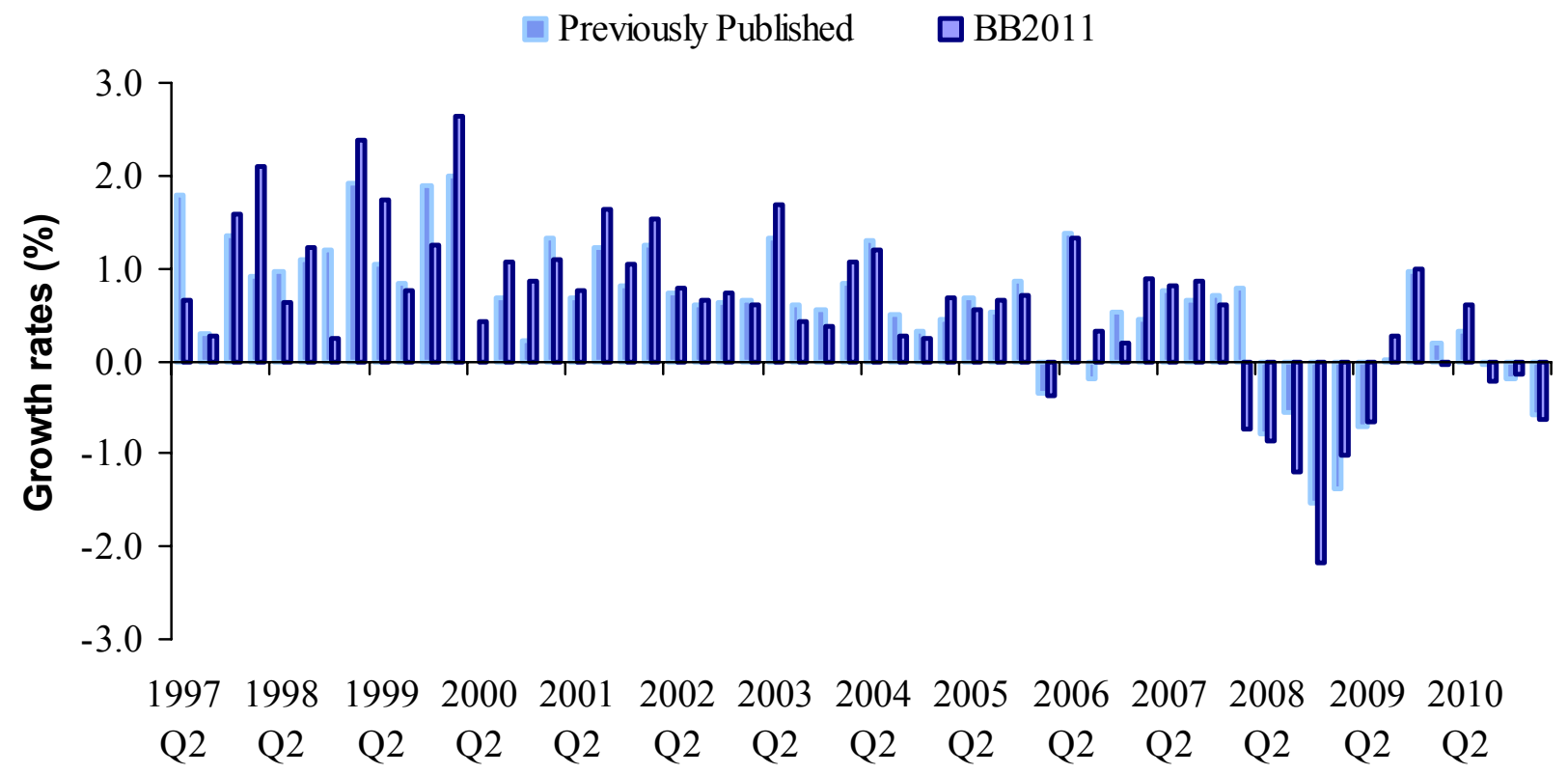

In addition to revisions brought about by the switch from RPI to CPI-based deflation, the supply and use balancing process affected current price totals of household final consumption, particularly in 2008 and 2009. The balancing process also led to some reclassification of elements of household final consumption, which in turn meant they were subject to different sub-category (COICOP) deflators, compared with the previous methodology. So the balancing process impacted on the household consumption total and some of its components in both current and, indirectly, chained volume terms. For further information, see the note on household expenditure estimates that is also published alongside the Quarterly National Accounts. Gittins and Clancy (2011).

There have been few significant revisions to the path for growth of gross fixed capital formation in the latest release. This reflects the decision to defer proposed improvements to the method of deflation due to the need for further quality assurance of the methodology. 
Revisions to general government final consumption are largely due to changes in deflation methodology.

The trade components have been most influenced by trade-specific reclassification as well as the implementation of a new deflation methodology, as described in Drew (2011). These changes have revisions particularly to the growth rates of exports of goods and services, more so than for imports of goods and services. This has fed through to revisions to the contribution of net trade to GDP growth, particularly in 2006, 2007, 2009 and 2010.

\section{Chart 7 Contribution of net trade to GDP growth (percentage points)}

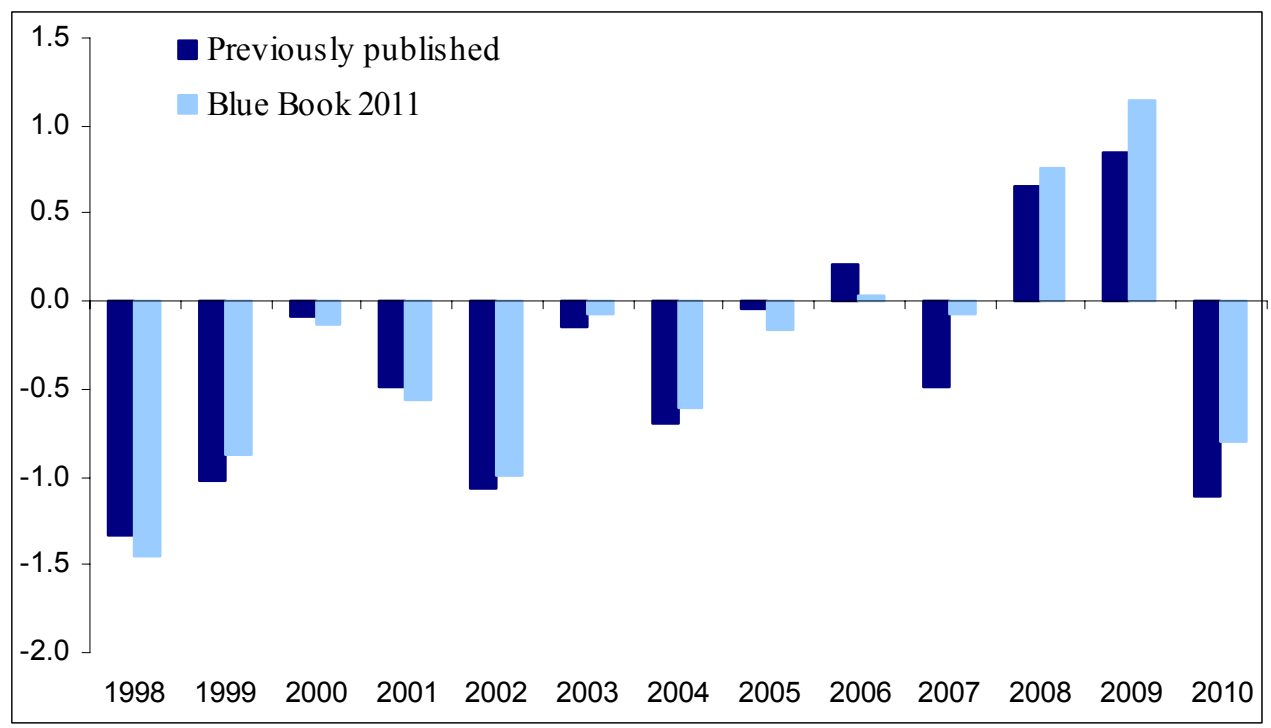

\section{Output components}

The latest release has seen the weights reflecting the various industries' contribution to the economy updated as a result of the move to the new industrial classification (SIC07). The production industries are now estimated to comprise 15.4 per cent of the economy in the base year of 2008, a reduction of 1.8 percentage points from the previous estimate which applied to 2006 . Some activity previously classified within services has now been reclassified to construction meaning that the latter's share of the economy has increased by 1.3 percentage points to 7.6 per cent. Nevertheless, the service industries still dominate output and are now estimated to contribute 0.5 percentage points more to GVA, (76.3 per cent in total). 


\section{Chart 8 Revisions to contribution to GDP growth by broad industry grouping (percentage points)}

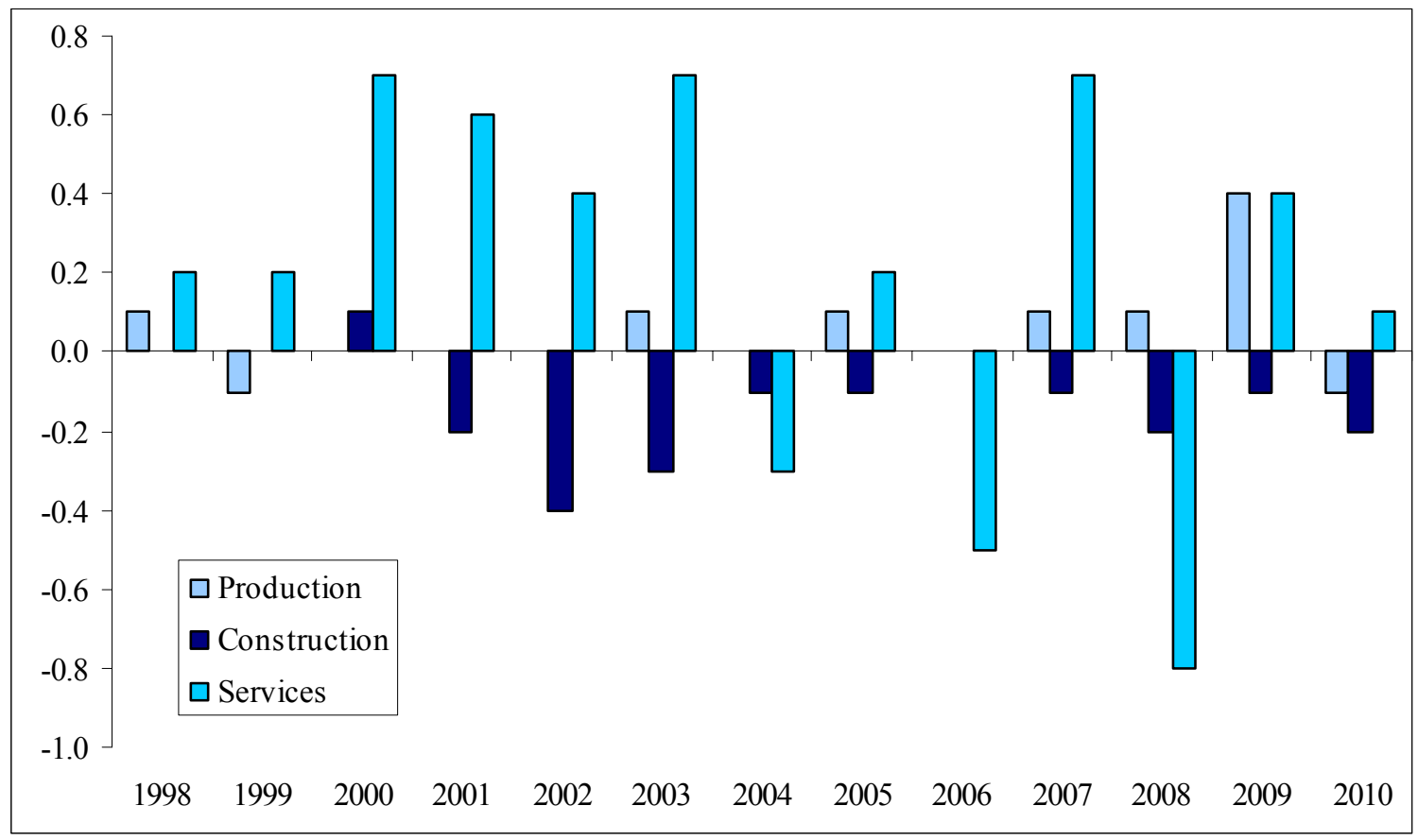

The contribution to growth from the production industry remains broadly unchanged, with the exception of 2009 , despite having the largest change to its weight. The revisions to contributions to growth from the construction industry are also relatively limited, though there is a period of more marked revision during 2001, 2002 and 2003. Finally, despite the smallest of the revisions being seen in the service industries, their weight led to them having the largest revisions to their contribution to growth.

Across the years, the service sector has shown the strongest contribution to GDP growth, which is to be expected given its significant weight. However, in 2008 the service sector made a much more modest, negative contribution to growth. In 2009, the production and construction sectors made more marked negative contributions to growth, compared to the absolute scale of these industries' contributions in previous years. In 2008 and 2009, all three main sectors made negative contributions to GDP growth - this had not happened in the preceding years back to 1998 .

\section{Income components}

Only nominal estimates of income components are published. The major impact has been through revised data for 2008, 2009 and 2010, when new data from HM Revenue and Customs and from the Annual Business Survey were taken on through the supply and use balancing process. 


\section{Chart 9 Revisions to GDP growth in current prices (percentage points)}

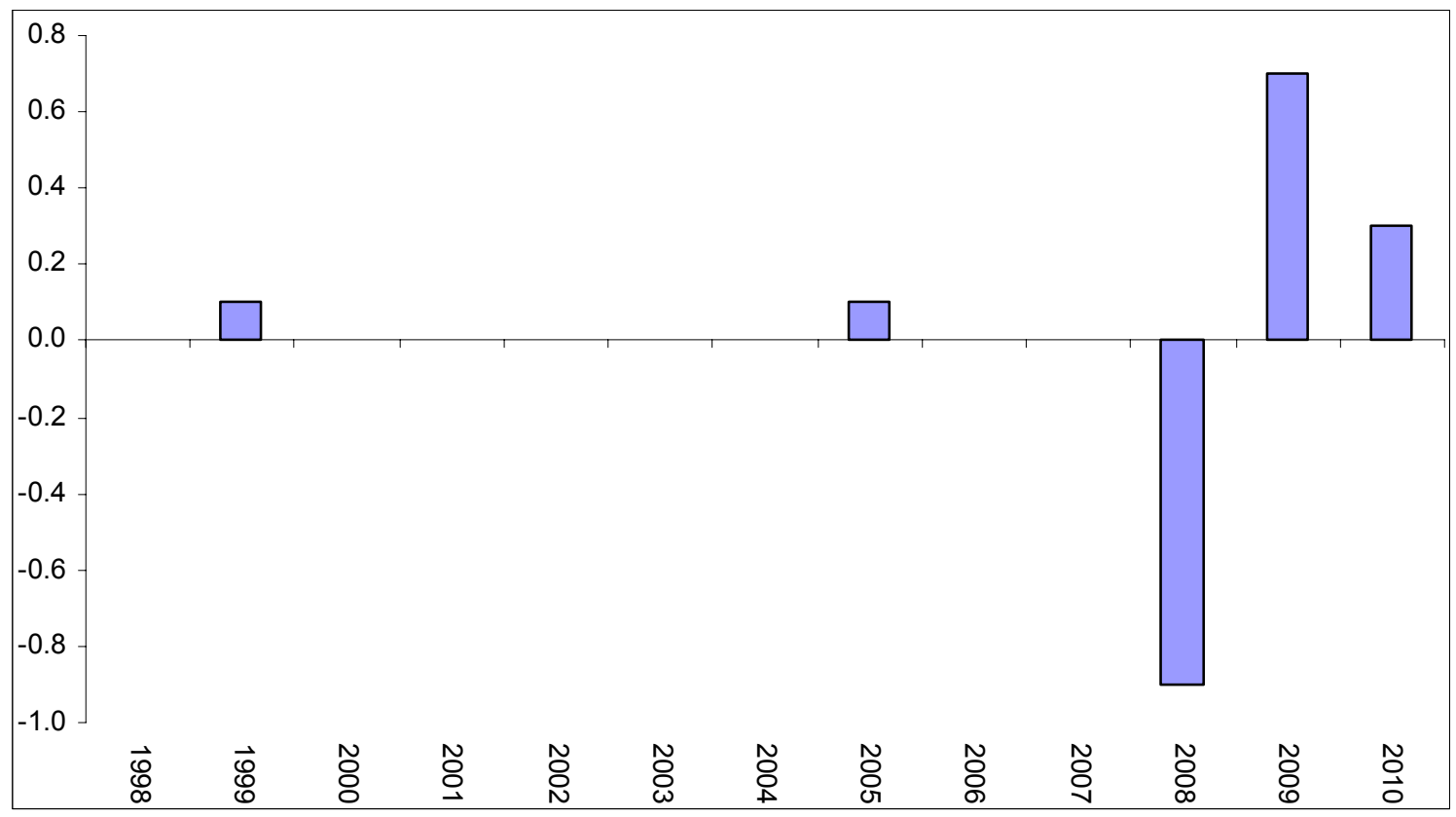

While the overall revisions to the current price income measure were small prior to 2008 , there were non-negligible changes in some of the income components. However, these tended to offset, resulting in the relatively small overall revisions in the earlier years. They largely stemmed from the rebalancing of supply and use tables which took place as a result of moving to the new industrial classification.

Chart 10 Change in contribution of income components to GDP growth in current prices (percentage points)

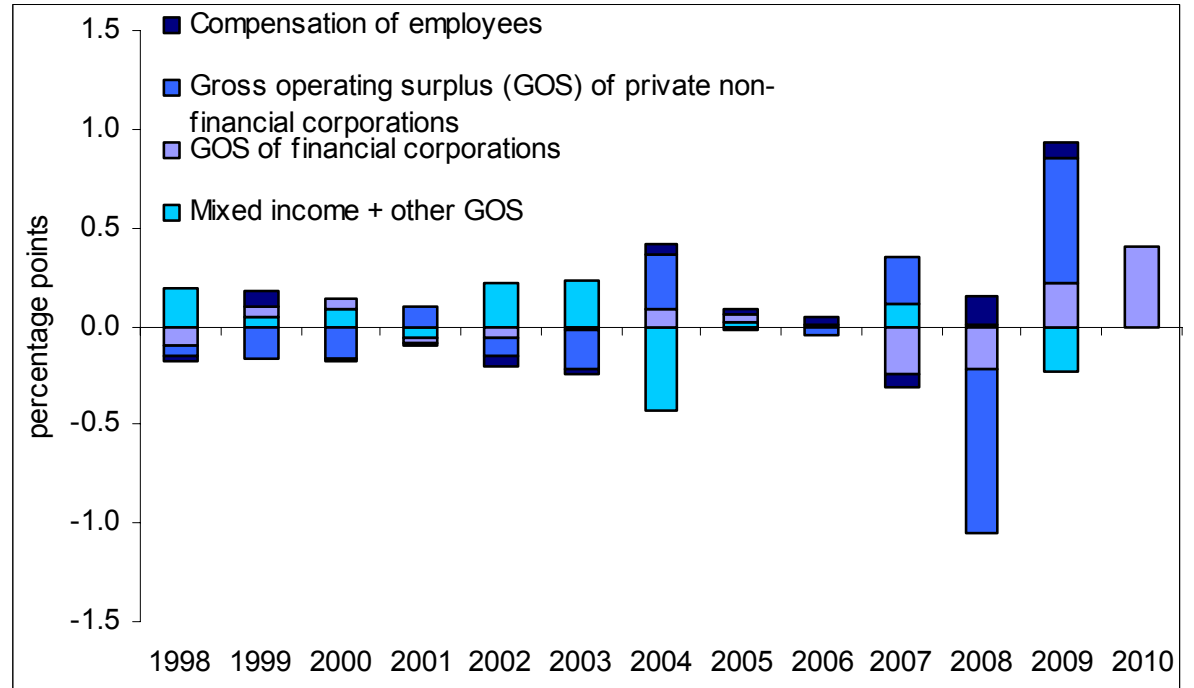

Despite compensation of employees making up over half of income, there have been relatively small revisions to this component. However, the revisions in 2008 and 2009, as a result of taking on the latest information from HMRC tax records, have resulted in the share of compensation of employees rising slightly in 2008, 2009 and 2010. Conversely, the share of private non-financial corporations' gross operating surplus has fallen slightly in 2009 and 2010 , though it has been in 
longer term decline, falling from 21 per cent in 1997 to 17 per cent in 2010 . These two components make up over 70 percent of the GDP as estimated by income.

\section{Conclusion}

The Quarterly National Accounts for the second quarter of 2011 are based on a number of methodological improvements:

- it is the first time that the National Accounts have been published using the revised Standard Industrial Classification 2007 (SIC07), providing an expanded coverage of the service industries.

- improved deflation methodology has been incorporated.

- the reference year and base year are 2008 , bringing them back to normal practice and completing the catching up of the lag which had opened up in earlier years.

- new annual benchmark data have been incorporated for 2009 , along with revised estimates of the benchmarks for earlier years.

The main revisions to estimates which stem from these and other changes are set out and described as in the preceding sections.

\section{Contact information}

Peter.patterson@ons,gsi.gov.uk 01633456451

Pete.lee@ons.gsi.gov.uk $\quad 01633456713$

Malindi.myers@ons.gsi.gov.uk 01633455986

\section{Acknowledgements}

The authors would like to thank the following ONS colleagues for their assistance in putting together this article:

Ole Black, Andrew Botterill, Gareth Clancy, Glenn Everett, Peter Gittins, Joe Grice, Craig McLaren, Kate Marks, Aileen Simkins, Matthew Swannell, Richard Tanguy, Andrew Walton

\section{References}

Beadle J (2007). 'Modernising the UK's National Accounts', Economic and Labour Market Review, April 2007, Volume 4 No1, pp32-38. Available at: http://www.ons.gov.uk/ons/rel/elmr/economicand-labour-market-review/no--4--april-2007/modernising-the-uk-national-accounts.pdf

Gittins P and Clancy G (2011): Blue Book 2011: Improvements to Household Expenditure Estimates. Available at: http://www.ons.gov.uk/ons/rel/consumer-trends/blue-book-2011-improvements-to-household-expenditure-estimates/q2-2011/art---blue-book-2011--improvementsto-household-expenditure-estimates.html 
Drew S (2011). 'Deflation Improvements in the UK National Accounts'. Non-journal article, ONS. Available at: http://www.ons.gov.uk/ons/rel/naa1-rd/national-accounts-concepts--sources-andmethods/august-2011/deflation-improvements-in-the-uk-national-accounts.pdf

Everett G (2011).'Methods changes in the 2011 Blue Book', ONS. Available at: http://www.ons.gov.uk/ons/rel/naa1-rd/united-kingdom-national-accounts/method-changes-in-bluebook-2011/index.html

Humphries S (2008) 'Modernisation of the UK's National Accounts: progress and plans for Blue Book and Pink Book 2008, Economic and Labour Market Review, June 2008, Volume 2, No 6, pp 30-32. Available at: http://www.ons.gov.uk/ons/rel/elmr/economic-and-labour-market-review/no--6-june-2008/modernisation-of-the-uk-s-national-accounts--progress-and-plans-for-blue-book-andpink-book-2008.pdf

Hughes J, James G, Evans A and Prestwood D (2009). 'Implementation of Standard Industrial Classification 2007: December 2009 update', Economic and Labour Market Review, December 2009, Volume 3, No 12, pp 51-55. Available at: http://www.ons.gov.uk/ons/rel/elmr/economic-andlabour-market-review/no--12--december-2009/economic---labour-market-review.pdf 